\section{DIGITAL COMMONS \\ @ UNIVERSITY OF SOUTH FLORIDA}

Journal of Practitioner Research

\title{
What First-Year Teachers Really Want from Principals During Their Induction Year: A Beginning Teacher Study Group's Shared Inquiry
}

\author{
Patricia J. Norman \\ Trinity University, pnorman@trinity.edu \\ Sara A.S. Sherwood \\ Trinity University, ssherwoo@trinity.edu
}

Follow this and additional works at: https://digitalcommons.usf.edu/jpr

Part of the Elementary Education and Teaching Commons

\section{Recommended Citation}

Norman, Patricia J. and Sherwood, Sara A.S. (2018) "What First-Year Teachers Really Want from Principals During Their Induction Year: A Beginning Teacher Study Group's Shared Inquiry," Journal of Practitioner Research: Vol. 3 : Iss. 2 , Article 7. https://doi.org/10.5038/2379-9951.3.2.1074

Available at: https://digitalcommons.usf.edu/jpr/vol3/iss2/7

This Practitioner Research is brought to you for free and open access by the Open Access Journals at Digital Commons @ University of South Florida. It has been accepted for inclusion in Journal of Practitioner Research by an authorized editor of Digital Commons @ University of South Florida. For more information, please contact digitalcommons@usf.edu. 


\title{
What First-Year Teachers Really Want from Principals During Their Induction Year: A Beginning Teacher Study Group's Shared Inquiry
}

\begin{abstract}
University teacher educators have a role to play in helping their graduates manage the transition from formal teacher preparation to independent teaching. This study focuses on a shared inquiry that five first-year elementary teachers conducted while participating in a monthly study group facilitated by two teacher educators from their teaching preparation program. The novices regularly perceived a lack of support from their campus administrator, including failing to give the beginning teachers permission to carry out teacher research projects they had designed. After analyzing the degree and kinds of support that they did or did not receive from their principals, the beginning teachers developed four recommendations for principals to help novices feel wellsupported during their initial year of teaching, including (1) developing productive relationships with novices, (2) helping novices becoming insiders to the campus, (3) being a visible presence in beginning teachers' classrooms, and (4) establishing and/or sustaining a professional learning community on the campus.
\end{abstract}

\section{Introduction}

The demands facing novice teachers are well documented. Many times assigned the most challenging classes and students (DePaul, 2000), they often feel isolated and overwhelmed in their first year on the job (Rogers \& Babinski, 2002) as they are expected to know and be able to do what an experienced veteran does (Brock \& Grady, 2007). The high turnover rate of new and early career teachers is concerning. In order to retain new teachers, novices need help making the transition to independent teaching. School-based mentoring programs have been one such retention strategy. However, universities are also being called on to design and provide induction support for their graduates (Alliance for Excellent Education, 2004). In her study of 53 award-winning first year teachers, DePaul (2000) found that the novices wanted to maintain connections with their teacher preparation program.

As co-coordinators of the elementary Master of Arts in Teaching (M.A.T.) program at Trinity University, we are deeply committed to helping our graduates manage the transition from formal teacher preparation to independent teaching. To counteract feelings of isolation that they often experience once in their own 
classrooms, we invite our graduates to participate in a monthly beginning teacher study group. Sessions are designed to extend reflective practices that participants engaged in as candidates in the M.A.T. program.

This study focuses on an action research project that graduates conducted as part of the beginning teacher study group. Action or practitioner research is "the systematic, intentional study of one's own professional practice" (Fichtman Dana, 2016, p.1). Educators frame a researchable question, collect data, then analyze that data to improve their practice and students' learning (Dana \& Yendol-Hoppey, 2009). Action research has the potential to serve as a powerful tool for beginning teachers, particularly those who find themselves in schools where they feel professionally isolated.

We had engaged the previous year's study group participants in an action research project that culminated in a Teacher Research Symposium held at the university where participants shared their inquiry stories and findings with current teacher candidates, alumni, family, friends and colleagues. Based on positive feedback from that year's study group participants, we planned to engage the following year's study group members in practitioner research as well. However, when three of the five members were unable to secure district and/or school-level permission to study their practice/students' learning, we designed a shared inquiry project around one of the most significant challenges that they faced in their first year of teaching -- the degree and kinds of support that they did or did not receive from their school administrator.

After describing the context of the study group, the five beginning teachers who participated, and the ways that we approached this shared inquiry, we offer the recommendations that the novice teachers developed for retaining highly motivated, capable early career teachers both in the profession and on their school campus.

\section{Context}

At Trinity University, we offer three induction supports to our graduates: a beginning teacher study group; an annual Summer Curriculum Writing Institute; and a summer seminar on critical friendship and facilitative leadership. In this article, we focus on the first initiative, the beginning teacher study group for elementary graduates in their first year of teaching.

Our teacher candidates' transition from their formal teacher preparation to their own classrooms can be uniquely challenging. As graduate students in the 
M.A.T. program, they are placed in a cohort of 10-15 candidates while completing a year-long, unpaid internship with a mentor in one of our professional development schools. The program is designed to help the cohort develop a strong professional learning community where we develop an agreedupon set of norms to support members in engaging in serious, sustained inquiry (Schwab, 1976). Moreover, their internship placements in our partner schools allow them to experience professional learning community in a school setting. As Darling-Hammond notes, teachers "want to be in environments where they are going to be successful with students, where they're getting help to do that, where they have good colleagues, where they're working as a team" (in Scherer, 2012, p. 23). Professional Development Schools offer that kind of collaborative, supportive learning community that encourages inquiry into practice (Dresden, Kittleson \& Wenner, 2014).

When Trinity graduates enter their own classrooms, they often find themselves in school contexts that do not support the shared inquiry that they experienced in their teacher preparation program nor the supportive learning community they enjoyed at their internship site. Perhaps not surprisingly, their school campuses, like so many in the United States, are typically characterized by professional norms of autonomy, politeness, isolation and non-interference (Lortie, 1975; McLaughlin \& Talbert, 2001).

\section{Beginning Teacher Study Group}

As noted earlier, the beginning teacher study group reflects practices that participants experience as teacher candidates in Trinity's M.A.T. program. The monthly two-hour sessions are organized around the following components:

- Dine and Unwind - the university identifies induction funds to provide dinner for participants. We informally reconnect over the meal.

- Reflections - written feedback is gathered at the end of each session. Each participant is asked to write a short reflection on their thoughts about the meeting that evening. These reflections are usually a sentence to a paragraph in length. Examples of written feedback from the participants in this study included:

- It's so amazing that people will come and spend an hour trying to help me wrap my mind around what's going on in my room and help me problem solve. I'm really grateful to have such thoughtful, encouraging teachers in my life.

- It feels great to be able to share and learn in a safe place. I feel like I can finally be understood here. 
- I really enjoyed [participant] sharing her struggle today - I feel like she is working so hard to care for and support her students, and I appreciated her making such an effort to 'let us in' to her thoughts.

We collect their written reflections for several reasons. First, leaving the last five minutes for participants to gather their thoughts helps them clarify their "take aways." Second, gathering participants' feedback helps the facilitator better understand how they made sense of a session, what they valued and any concerns they experienced in order to plan for the next month's session. Finally, because a full month typically passes before the group reconvenes, anonymous excerpts of the written feedback are shared early on in the next session in order to remind participants what we were thinking and feeling as a result of the previous month's work together. Sharing these excerpts serves to close the feedback loop.

- Digging In - the bulk of the two hours is devoted to Digging In where we engage in reflective practices. These vary from using protocols from the School Reform Initiative (www.schoolreforminitiative.org/protocols) to help novices work through dilemmas of practice to engaging in specific aspects of action research.

- Stepping back - we end each session with an open-ended invitation to record in writing what is on participants' minds after our shared learning. We call it Stepping Back to signal to participants that after dancing on the dance floor together during Digging In, they can step back from the dance floor in order to reflect on the experience. Anonymous excerpts from those written reflections, as noted earlier, are then shared at the next month's meeting.

The study group structures are specifically designed to promote professional learning -- "an internal process in which individuals create professional knowledge through interaction with this information in a way that challenges previous assumptions and creates new meaning" (Timperley, 2011, p. 5).

\section{Participants}

The five beginning teachers who voluntarily participated in the study group taught in five different public elementary schools in different grade levels in five different districts in the surrounding community. Their school settings were diverse, including rural, suburban and urban communities. While the size of their elementary campuses varied, with student enrollment ranging from a low of 430 to a high of 788, all participants' campuses had the same number of 
administrators - one principal and one assistant principal. With the exception of Lisa, whose principal was new to the principalship, the other four participants' principals had 10 or more years of experience in that role (see Table 1).

Table 1

Participants in Beginning Teacher Study Group

\begin{tabular}{|c|c|c|c|c|}
\hline $\begin{array}{l}\text { Beginning } \\
\text { Teacher }\end{array}$ & Grade Level & $\begin{array}{c}\text { School } \\
\text { Context }\end{array}$ & $\begin{array}{c}\text { Number } \\
\text { of } \\
\text { Students }\end{array}$ & $\begin{array}{c}\text { Number of } \\
\text { Administrators }\end{array}$ \\
\hline Kendra & kindergarten & $\begin{array}{c}\text { rural } \\
\text { PK-5 } \\
\text { Grade }\end{array}$ & 634 & $\begin{array}{l}1 \text { principal } \\
1 \text { assistant } \\
\text { principal }\end{array}$ \\
\hline Jenny & $\begin{array}{l}\text { fifth grade } \\
\text { inclusion }\end{array}$ & $\begin{array}{c}\text { suburban } \\
\mathrm{K}-5^{\text {th }} \text { grade }\end{array}$ & 508 & $\begin{array}{r}1 \text { principal } \\
1 \text { assistant } \\
\text { principal }\end{array}$ \\
\hline Simone & second grade & $\begin{array}{c}\text { suburban } \\
\mathrm{PK}-5^{\text {th }} \text { grade }\end{array}$ & 788 & $\begin{array}{c}1 \text { principal } \\
1 \text { assistant } \\
\text { principal }\end{array}$ \\
\hline Anita & fifth grade & $\begin{array}{c}\text { urban } \\
\mathrm{PK}-5^{\text {th }} \\
\text { grade }\end{array}$ & 430 & $\begin{array}{l}1 \text { principal } \\
1 \text { assistant } \\
\text { principal }\end{array}$ \\
\hline Lisa & fourth grade & $\begin{array}{c}\text { military } \\
\text { PK-5 } 5^{\text {th }} \text { grade }\end{array}$ & 625 & $\begin{array}{l}1 \text { principal } \\
1 \text { assistant } \\
\text { principal }\end{array}$ \\
\hline
\end{tabular}

All five were expected to participate in district- and/or school-level mentoring programs. The participants remarked, however, that these school and district-led offerings stood in sharp contrast to the university-based study group that promoted professional learning through inquiry. As an example, Simone was required to attend monthly sessions organized around specific chapters in a book on beginning teachers. During Dine and Unwind, Simone described how the facilitator launched one month's session focused on assessment: "Okay, today we're going to talk about the assessment piece. It's really important that you assess your students. There are two kinds of assessment -- formative and summative." The facilitator proceeded to incorrectly state that summative assessments are ongoing and formative ones include the state's end-of-year exams. Simone explained that she felt compelled to correct the facilitator, noting that the opposite is true. Five minutes of silence descended as the facilitator reread the pages that she had been paraphrasing. Upon her re-reading, the facilitator 
did acknowledge that it appeared that Simone was correct. The facilitator encouraged Simone and the other first year teachers to try to use both forms of assessment. While Simone felt the district program was well-intentioned, the text offered only the most basic of information, something she would have appreciated as an undergraduate in an introductory teaching course.

In contrast, Simone and her four fellow first-year teachers looked forward to returning to the university where we met monthly. In fact, two months into their tenure as teachers they requested meeting more often, thus we began holding twice-monthly sessions. One was held at the university while the other was held at a local restaurant where we discussed and analyzed their dilemmas of practice.

\section{Shared Inquiry}

The five beginning teachers were excited about engaging in action research and appreciated the support we provided in the university-based study group to help them frame a researchable question. The university provided copies of The Reflective Educator's Guide to Classroom Research: Learning to Teach and Teaching to Learn through Practitioner Inquiry (Dana \& Yendol-Hoppey, 2009). In the fall semester, participants first identified initial issues of interest that grew out of their classroom practice. After narrowing their focus to a single wondering, the five novices each crafted their own researchable question then designed a plan to systematically study that issue within their classroom.

Before formally beginning to collect data in the spring, we encouraged the teachers to inform their principal about their action research plan. Surprisingly, three of the five novices were unable to secure district and/or school-level permission to study their practice/students' learning. The three were frustrated and disappointed, unable to understand how an administrator would not support their efforts to improve their teaching practice through action research.

In response to this unexpected glitch in moving forward, we discussed the focus of future study group sessions since action research was no longer an option for all participants. In the course of that conversation, the novices surfaced several challenges that they had encountered with their campus principal beyond their perceived lack of support of the teacher research initiative. As we used protocols in subsequent study group sessions to help individual participants work through professional challenges, we continually identified the campus administrator as a central figure in their first-year experience. 
We designed a shared inquiry around one of the most significant challenges that they faced in their first year of teaching -- the degree and kinds of support that they did or did not receive from their school administrator. Drawing on field notes that the two of us had taken during study group sessions, we analyzed those notes together with the novices, looking for patterns in their interactions with principals. All five beginning teachers felt that the quality of support from and communication with their administrator was vitally important to their ability to function well in their classroom and school. Their interest/willingness to remain in their current teaching position at the end of their first year rested on the degree to which they felt valued and supported by their principal. Our own analysis reflected recent research findings, namely that "teachers' perceptions of the school administration has by far the greatest influence on teacher retention decisions" (Boyd, Grossman, Ing, Lankford, Loeb \& Wyckoff, 2011, p. 303).

\section{Recommendations to Principals for Retaining Beginning Teachers}

As a result of our shared inquiry, the beginning teachers developed a set of recommendations designed to help principals better understand and meet the professional learning needs of novices on their campus. The four recommendations -- which grew out of the five novices' direct experiences as beginning teachers -- include (1) developing productive relationships with novices, (2) helping them becoming insiders to the campus, (3) being a visible presence in their classrooms, and (4) establishing and/or sustaining a professional learning community on the campus.

Before discussing each recommendation below, the beginning teachers themselves were clear both with us and in sharing these findings during different presentations that their recommendations in no way imply that they did not have any of these things themselves. They were all in unique situations where they enjoyed wonderful support in some ways and knew that they could have benefited in other ways. They simply determined that the four recommendations would have made a significant difference for them in their first of teaching and made each of them feel wonderful about remaining at their school campus (which four of the five did).

\section{Develop Strong Relationships with Novice Teachers}

Novices care so much about what administrators think of them. Many beginning teachers are nervous every time they converse with their principal. The more their administrator talks with them, the less nervous they become. It is 
therefore imperative that principals develop positive working relationships with their new teachers through meaningful, regular interactions. All five beginning teachers believed that getting to know their administrators and the administrators getting to know them would help the beginning teachers work better with their campus principal.

Beginning teachers are motivated to get to know their campus leader. Because they are new to both the setting and the profession, their lack of familiarity with those in authority can leave them feeling uncomfortable. Such unresolved discomfort can lead them to avoid seeking out essential support and information that they need to be successful. As any principal can attest, new teachers have many questions. Feeling unsafe to ask questions, novices might attempt to figure things out on their own, potentially leading to mistakes that have consequences for both their students and their own professional learning.

As Simone noted, having her principal be fully present when interacting with her would have helped them build a trusting, respectful relationship. For example, when she would stop by her administrator's office and ask, "Do you have a minute?" her principal would often respond "sure" but then continue to read through paperwork or answer emails. Recognizing how complex and demanding an administrator's job is, Simone appreciated the principal's attempt to be responsive in the moment. However, because the principal was not fully present, the novice walked away feeling like a burden. Simone was not the only intern who felt this way. When Jenny felt that she was not doing a good job in her first year, she did not think of going to her principal. She thought of the study group and reaching out to us as her former supervisors because of what we do at Trinity and how we approach learning to teach. She trusted her peers and faculty to help her. That level of trust was missing on her school campus. Lisa, too, felt that when she brought up a concern to her principal, it often felt like Lisa was given the shortest possible solution, leaving her with the impression that her principal did not have time for her to work through challenges.

These anecdotes illustrate how attuned novices are to their every interaction with their administrator. Making the commitment to be fully present not just in body but mind and heart as well, will help beginning teachers feel valued and understood.

\section{Help Novices Become Insiders to the Campus}

Although teacher preparation programs can help beginning teachers learn to plan, to teach, and to assess student learning, the one thing that formal 
preparation programs cannot do is to help their candidates know all of the practical information that is specific to any given campus. Because novice teachers are held to the same standards as their more experienced peers, administrators must help novices become insiders to their campus. Novices need access to the details that they cannot possibly know as newcomers to a campus. Otherwise, beginning teachers are left to guess how to complete forms and reports, productively and accurately participate in school wide events and access resources that could improve their efficiency and effectiveness.

Although novices can and do elicit information from their grade level team, they worry that their constant questions feel annoying to their colleagues. Because they can feel like deadweight taking and needing so much from their more experienced peers, beginning teachers may withhold asking important questions. Consequently, they learn essential information after rather than before they need that information to direct their decision-making. For instance, Kendra learned in April that she should have been adding narrative feedback to her students' electronic report cards all year. For three grading periods, she had not known this was possible or required. No one had told or taught her how to do this. Furthermore, Kendra shared that during state testing, a child in her classroom vomited. When she buzzed the office for custodial assistance, she was admonished for contacting the office. Apparently, teachers were not supposed to buzz the office during state testing but no one had ever mentioned this change in standard procedure. Kendra was not the only one to experience this challenge of finding information out after the fact. Anita found out after administering the state exam to her students that she was allowed to read any question or response stem aloud to a child. She only found this out by reading the instructions during a different state assessment she gave at a later date!

Having open access to an administrator is crucial to obtaining campusspecific information. The novices noted that while a principal may ask teachers during faculty meetings if they have questions, this venue does not lend itself to novices doing so. Beginning teachers do not always feel comfortable raising what they intuit may be questions that only pertain to them, particularly if a faculty meeting is running long. Because novices always have questions, principals might consider allocating time immediately following a meeting to answer questions so that novices do not feel like they are holding up their colleagues. Principals might also consider another helpful approach that the principal at one of Trinity's partner campuses employs. The campus administrator meets monthly with new teachers across their first year to walk them through the calendar for that month, providing crucial information about how special events work and the role they 
should play. Carving out small amounts of time to help novices become insiders can yield a big payoff in the quality of their work.

\section{Be in Novices' Classrooms}

The five beginning teachers want administrators to understand that novices really need principals to be in their classrooms. Even though first year teachers sometimes feel nervous when campus leaders visit, novices value administrators' feedback, both what there is to celebrate in their teaching as well as suggestions for continued improvement.

Three of the five beginning teachers lamented to their campus peers that they wanted their principal to come into their classroom more often. To the novices' surprise, their colleagues explained that the principal's absence from their classroom should be viewed as a "good thing" since the administrator only visited teachers who experience difficulty. The beginning teachers had a hard time believing that no feedback was an indicator of their strength as educators. They often felt anxious due to their administrator's absence from their classroom, like "we hope we didn't do something wrong" or "we hope we don't get in trouble."

At one novice's campus, teachers called the principal's visits to classrooms a "drive by." The visits had been nicknamed "drive by" because the administrator came into a classroom then never shared anything with the teacher afterwards. The five beginning teachers, however, craved substantive feedback on their teaching and students' learning. They had received daily and weekly feedback from Trinity faculty and their mentor teachers during their year-long internships. The novices knew how helpful feedback is to support their growth. They looked to their administrators to provide it and noted that principals must come into their classrooms in order to know what is happening instructionally.

\section{Develop Professional Learning Community on Campus}

Finally, the novices recommend that principals work to establish or strengthen a professional learning community on their campus. For the five beginning teachers who completed Trinity University’s M.A.T. program, professional learning community meant placing students at the center of their professional work. They needed their school leaders to continually remind both them and their colleagues to make decisions driven by what is best for students. They needed their campus administrator to expect and insist that everything done be in the service of students' learning. They also needed their campus leader to 
engage faculty in uncomfortable conversations to surface teachers' underlying values, assumptions and beliefs.

When such conversations did not happen, the novices found themselves in vulnerable situations. For example, one of the study group participants was on a large grade level team. The team divvied up planning responsibilities by content area to particular team members who were then expected to craft weekly plans and share them for every team member's use. The study group participant realized that one of her grade level colleagues was really struggling to plan on her own. Even though she was a novice herself, Simone offered to and began co-planning with the teacher. When other members of her team found out that Simone was supporting her colleague, they privately told Simone to stop helping her colleague because her peer was simply "taking her ideas." Simone could not understand why her colleagues wanted to thwart her efforts to support her struggling colleague since she felt it was in students' best interest to have the students in both classrooms experience high-quality learning opportunities.

Believing that she could continue to support her grade level peer but faced with mounting opposition from other team members, Simone went to her principal to share her concern that she was being asked to stop co-planning. The principal simply suggested that Simone ignore those who were telling her to stop. This advice failed to address the larger concerns that had surfaced about the quality of the professional learning community at Simone's school. What did it say about their campus community that teachers believed that they should deliberately allow their peer (and by extension, the peer's students) to fail?

Simone was not the only participant who was concerned about the lack of professional learning community on her campus. Kendra, for example, was really excited when her campus administrator announced that the staff would engage in a year-long book study. Having appreciated how discussions of readings during her M.A.T. graduate courses had helped to inform her teaching practice, Kendra looked forward to engaging in text-based discussions with her school-based colleagues. The principal had assigned the first chapter before the next faculty meeting. Kendra had not only read the first chapter but several additional chapters because she found herself deeply immersed in the text. Upon learning that Kendra had read not only the required chapter but additional pages, her peers derided her, calling her the principal's pet. They could not believe she had done the reading. Kendra was disappointed to learn that most of the teachers had not. 


\section{Discussion}

As the vignettes above illustrate, the degree and quality of an administrator's interaction with her novice teachers is essential to help them feel supported and positioned to tackle the complex intellectual work of teaching. Although the five novices did not always feel sufficiently supported by their principal, their participation in the university-based beginning teacher study group helped to mitigate that perceived lack of support and served as a powerful vehicle for their professional learning. Universities are well positioned to help novices make the transition to independent teaching. University teacher educators already have established relationships with their graduates, knowing their strengths and areas for continued growth, thus they can offer novices targeted support once in their own classroom. In this sense, university teacher educators create a bridge between novices' pre-service and induction experiences.

The M.A.T. graduates appreciated the beginning teacher study group as an opportunity to continue to participate in the professional learning community established during their formal teacher preparation program. The beginning teacher study group provided participants with a "safe place" to go to where they could take their own and their peers' professional learning seriously, giving them an alternative to the sometimes competitive school environment in which they worked. Study group participants also appreciated being able to build on their shared vision of teaching and learning already established through their M.A.T. program. Finally, they really valued the two-hour block of uninterrupted time each month to jointly problem solve. The fast-paced world of schools often left them feeling like they rushed to possible solutions without first better understanding the nature of the problem and all of the issues embedded within it. Using shared inquiry as well as protocols to work through questions of practice gave them structures to examine those challenges more systematically. By informally extending preservice teacher learning into the induction year, novice teachers can continue to refine and expand their teaching practice. 


\section{References}

Alliance for Excellent Education. (2004). Tapping the potential: Retaining and developing high-quality new teachers. Washington DC: Alliance for Excellent Education.

Boyd, D., Grossman, P., Ing, M., Lankford, H., Loeb, S. \& Wyckoff, J. (2011). The influence of school administrators on teacher retention decisions. American Educational Research Journal, 48(2), 303-333.

Brock, B.L. \& Grady, M.L. (2007). From first-year to first-rate: principals guiding beginning teachers. Thousand Oaks, CA: Corwin Press.

Dana, N.F. \& Yendol-Hoppey, D. (2009). The reflective educator's guide to classroom research: Learning to teach and teaching to learn through practitioner inquiry. Thousand Oaks, CA: Corwin Press.

Dana, N.F. (2016). The relevancy and importance of practitioner research in comtemporary times. Journal of Practitioner Research, 1(1), 1-7).

DePaul, A. (2000). Survival Guide for New Teachers: How New Teachers Can Work Effectively with Veteran Teachers, Parents, Principals and Teacher Educators. Washington DC: Office of Educational Research and Improvement.

Dresden, J., Kittleson, J. \& Wenner, J. (2014). Clinically rich practices in teacher education: Review and recommendations. In J. Ferrara, J.L. Nath \& I.N. Guadarrama (Eds.), Creating visions for university-school partnerships. (pp. 43-60). Charlotte, NC: Information Age Publishing.

Lortie, D. (1975). Schoolteacher: A sociological study. Chicago: University of Chicago Press.

McLaughlin, M. \& Talbert, J. (2001). Professional communities and the work of high school teaching. Chicago: University of Chicago Press.

Rogers, D.L. \& Babinski, L.M. (2002). From isolation to conversation: Supporting new teachers development. Albany: State University of New York Press.

Scherer, M. (2012). The challenges of supporting new teachers. Educational Leadership, 69(8), 18-23.

Schwab, J.J. (1976). Genesis: A discussion of principles of inquiry [cassette recording]. East Lansing: Michigan State University.

Timperley, H. (2011). Realizing the power of professional learning. McGraw-Hill Education, UK. 